\title{
Revealed «Oncologic Markers» in the Sea Star Antibody Response to Horse-Radish Peroxydase
}

\author{
${ }^{1}$ Michel Leclerc and ${ }^{2}$ Patricia Otten \\ ${ }^{1}$ Independent Researcher, 556 Rue Isabelle Romée, Sandillon, France \\ ${ }^{2}$ Fasteris, Plan-les-Ouates, Switzerland
}

Received 2013-11-05, Revised 2013-11-11; Accepted 2013-11-16

\begin{abstract}
At least two genes found in the genome of Asterias rubens after immunizations to the antigen Horse-Radish Peroxydase (HRP), could play the role of oncologic markers: The first one (Igkappa chain V-V region T 1 S 107 B precursor) reveals myeloma; The second (B cell CLL/Lymphoma 9-like) as the first one has a kinship to the IgKappa gene subfamily.
\end{abstract}

Keywords: Asterias Rubens, Antibody Response, Igkappa Precursor Genes, Myeloma, Lymphoma

\section{INTRODUCTION}

Leclerc and Vincent (2013) the sea star genome with Swissprot data, revealed, for the first time, a sea star Igkappa gene, in response to HRP immunizations.

On the other hand, oncologic markers, of the IgKappa subfamily, were also found. At our knowledge, it is also the first time, that such phenomenon was described.

\section{MATERIAL AND METHODS}

Sea stars Asterias rubens were obtained from the Biology Institute (Gothenburg Univeristy). Immunizations and sequencing have already been described in precedent papers (Leclerc et al., 2011;
2013). In 2013 transformation of RNA intoc DNA and sequencing were performed at Fasteris(Switzerland).

\section{RESULTS AND DISCUSSION}

It appears that the gene: Igkappa chain $\mathrm{V}-\mathrm{V}$ region $\mathrm{T}$ 1 is present, in a significant manner in the genome of immunized sea star to the antigen HRP.

The following Table 1 gives its characteristics.

In the Table 2, we make reference to another oncologic marker: The B cell CLL lymphoma 9-like protein. Table 2 is following.

Table 1. Identities of Igkappa chain V-V region T1 between sea star and mouse

sp|P01637.1|KV5A5_MOUSE RecName: Full=Ig kappa chain V-V region T1; Flags: Precursor Length=128

Score $=26.6$ bits $(5 \overline{7})$, Expect $=8.0$

Identities $=10 / 22(45 \%)$, Positives $=16 / 22(73 \%)$, Gaps $=0 / 22(0 \%)$ Frame $=+2$

Query 314 RVILRIRPSQ*LNKYLTWWRRK 379

$\mathrm{RV}++\mathrm{SQ}+\mathrm{N}$ YLTW $+++\mathrm{K}$

Sbjct 38 RVTISCKASQDINSYLTWFQQK 59

Table 2. Identities of B cell CLL between sea star and mouse genomes.

$>$ sp|Q67FY2.1|BCL9L_MOUSE RecName: Full=B-cell CLL/lymphoma 9-like protein; Short=B-cell

lymphoma 9-like protein; Short=BCL9-like protein; AltName:

Full=BCL9-related beta-catenin-binding protein; AltName: Full=Protein BCL9-2

Length $=1494$

Score $=26.9$ bits $(58)$, Expect $=3.3$

Identities $=19 / 57(33 \%)$, Positives $=23 / 57(40 \%)$, Gaps $=7 / 57(12 \%)$ Frame $=+1$

Query 1 LQDRHGIRAR-----GLCQFVAARVAIWPPIDTPDTPRGPYPSFSHQCSSARVSRI 153

LQ HG A GL Q + +A+ PP D P P GP P H R+

Sbjct 1229 LQQPHGAMAPTGAGGPGLQQHYPSGMAL-PPEDLPTQPPGPIPPQQHLMGKGMTGRM 1284

Corresponding Author: Michel Leclerc, Independent Researcher, 556 Rue Isabelle Romée, Sandillon, France 


\section{CONCLUSION}

It is particularly interesting to find in the sea star genome such oncologic markers which are linked for the first one to mouse myeloma (Altenburger et al., 1980), for the second one to lymphoma (Toya et al., 2007). They are expressed in a significant manner in the sea star. It is advisable to ask if the sea star, itself possesses these markers, consequently to an immunization, like mammals and so reveal a disease.In the present time it is difficult to conclude. We just can say that it is the research of kappa genes in the sea star which have led us to this discovery. We expect that this last one will open a new field in the investigation of cancerology.

\section{REFERENCES}

Altenburger, W., M. Steinmetz and H.G. Zachau, 1980. Functional and non-functional joining in immunoglobulin light chain genes of a mouse myeloma. Nature, 287: 603-607. DOI: $10.1038 / 287603 \mathrm{a} 0$
Leclerc, M. and N. Vincent, 2013. A true new gene: An invertebrate antibody Igkappa gene. Am. J. Immunol., $\quad 1$ : 101-102. DOI : 10.3844/ajisp.2013.101.102

Leclerc, M., N. Kresdorn and B. Rotterb, 2013. Evidence of complement genes in the sea-star Asterias rubens. Comparisons with the sea urchin. Immunol. Lett., 151: 68-70. DOI: 10.1016/j.imlet.2013.02.003

Leclerc. M., S. Dupont, O. Ortega-Martinez, B. Hernroth and N. Krezdorn et al., 2011. Evidence of kappa genes in the sea-star asterias rubens (Echinoderma). Immunol. Lett., 138: 197-198. DOI: 10.1016/j.imlet.2011.01.016

Toya, H., T. Oyama, S. Ohwada N. Togo and I. Sakamoto et al., 2007. Immunohistochemical expression of the $\beta$-catenin-interacting protein $\mathrm{B} 9 \mathrm{~L}$ is associated with histological high nuclear grade and immunohistochemical ErbB2/HER-2 expression in breast cancers. Cancer Sci., 98: 484-490. DOI: 10.1111/j.1349-7006.2007.00430.x 